\title{
The association between physical activity and neck and low back pain: a systematic review
}

\author{
Ekalak Sitthipornvorakul • Prawit Janwantanakul • \\ Nithima Purepong $\cdot$ Praneet Pensri • \\ Allard J. van der Beek
}

Received: 25 July 2010/Accepted: 7 November 2010/Published online: 27 November 2010

(c) The Author(s) 2010. This article is published with open access at Springerlink.com

\begin{abstract}
The effect of physical activity on neck and low back pain is still controversial. No systematic review has been conducted on the association between daily physical activity and neck and low back pain. The objective of this study was to evaluate the association between physical activity and the incidence/prevalence of neck and low back pain. Publications were systematically searched from 1980 to June 2009 in several databases. The following key words were used: neck pain, back pain, physical activity, leisure time activity, daily activity, everyday activity, lifestyle activity, sedentary, and physical inactivity. A hand search of relevant journals was also carried out. Relevant studies were retrieved and assessed for methodological quality by two independent reviewers. The strength of the evidence was based on methodological quality and consistency of the results. Seventeen studies were included in this review, of which 13 were rated as high-quality studies. Of highquality studies, there was limited evidence for no association between physical activity and neck pain in workers and strong evidence for no association in school children.
\end{abstract}

E. Sitthipornvorakul · P. Janwantanakul $(\varangle) \cdot$ N. Purepong · P. Pensri Department of Physical Therapy, Faculty of Allied Health Sciences, Chulalongkorn University, Bangkok, Thailand e-mail: prawit.j@chula.ac.th

A. J. van der Beek

Department of Public and Occupational Health, EMGO Institute for Health and Care Research, VU University Medical Center, Amsterdam, The Netherlands

A. J. van der Beek

Body@Work, Research Center on Physical Activity, Work and Health, TNO-VUmc, Amsterdam, The Netherlands
Conflicting evidence was found for the association between physical activity and low back pain in both general population and school children. Literature with respect to the effect of physical activity on neck and low back pain was too heterogeneous and more research is needed before any final conclusion can be reached.

Keywords Spinal pain · Daily activity - Lifestyle . Systematic review

\section{Introduction}

Neck and low back pain are important health problems in the modern world [13, 45]. Approximately $14-71 \%$ of adults experience neck pain at some points in their lifetime and the 1-year prevalence rate for neck pain in adults ranges from 16 to $75 \%$ [15]. For low back pain, estimates for the lifetime prevalence range from 11 to $84 \%$, while those for 1-year prevalence range from 22 to $65 \%$ [45]. Neck and low back pain cause personal suffering, disability, and impaired quality of work and life in general, which can be a great socio-economic burden on patients and society [12, 21, 31, 32]. In the Netherlands, the total cost of neck pain in 1996 was estimated at 686 million US dollars [7] whereas, in 2006, Katz [27] proposed that the total cost of low back pain in the United States exceeds 100 billion US dollars per year.

Exercise or vigorous physical activities have a beneficial effect on neck and low back pain [18, 19, 26, 30]. Hayden et al. [18] found that strengthening exercise is effective in reducing pain and improving back function. Jensen [26] found that strengthening and fitness exercises were effective in reducing the prevalence of neck and back pain. Daily physical activity, which is physical activity at rather low to 
moderate levels, when performed sufficiently is widely known to have important health benefits [1]. However, modern living increases the tendency to have a more sedentary lifestyle. Reduced physical activity has been linked to several chronic health problems, including diabetes mellitus [2, 34], ischemic heart disease, stroke, breast cancer, colon/rectal cancer [2], and chronic musculoskeletal complaints [22]. The effect of physical activity on neck and low back pain is still controversial [4-6, 14, 20, 33, 42, 47].

No systematic review has been conducted on the relationship between physical activity and neck and low back pain. The aim of this paper was to systematically review the scientific literature to gain insight into the association between physical activity and neck and low back pain as well as the strength of evidence.

\section{Methods}

\section{Search strategy}

Publications were retrieved by a computerized search of the following databases: PubMed, CINAHL Plus with full text, The Cochrane library, Science Direct, PEDro, ProQuest, PsycNet and Scopus. The following keywords were used: neck pain, back pain, physical activity, leisure time activity, daily activity, everyday activity, lifestyle activity, sedentary, and physical inactivity. After inclusion of the articles based on the selection criteria, references were searched for additional articles. All published articles published between 1980 and June 2009 were eligible for inclusion in the review.

\section{Selection criteria}

A reviewer (ES) selected relevant articles from the articles retrieved with the search strategy. The selection criteria were

1. The study design was a cross-sectional or cohort study. Experimental studies were excluded.

2. The article was a full report published in English. Letters and abstracts were excluded.

3. Study samples were representative of a general population. Studies in athletes, patients or pregnant women were excluded.

4. The outcome included the association between physical activity and the presence of neck or low back pain.

5. Non-specific neck or low back pain was assessed in the study. Studies on neck or low back pain due to a definite herniated intervertebral disk and those on pain due to osteoporosis, cancer or other specific causes were excluded.
Methodological quality assessment

The articles that met the selection criteria were evaluated for methodological quality. Two reviewers (ES and NP) independently assessed the quality of each article by using the checklists for quality appraisal modified from previous systematic reviews of musculoskeletal symptoms [11, 23, 43]. Slightly different checklists were used for the quality assessment of different study designs (Table 1). Each item was scored as positive, negative (potential bias) or unclear (if insufficient information was available for a specific item). The scoring for each item of the two reviewers was compared. Disagreements between the reviewers on individual items were identified and discussed in an attempt to achieve consensus. If agreement could not be reached, a third reviewer (PJ) was consulted to achieve a final judgment. Methodological quality assessment was based on the percentage of positive items over the total number of items. A high-quality study was defined as scoring positive on $>50 \%$ of items and a lowquality study was defined as scoring positive $\leq 50 \%$ of items [11]. Only high-quality studies were included in the review.

\section{Data extraction and analysis}

For each article, the first author, year of publication, study design (and, if applicable, follow-up period), study population, participation rate, type and measurement tool of physical activity, measurement tool of neck or back pain and its recall period, results (the association between physical activity and neck or low back pain in terms of OR or RR), and conclusion were extracted. Data extraction was separately conducted for neck and low back pain.

Strength of evidence

The strength of evidence was divided into five levels based on the study design, the number of studies, and the quality score of studies [11]:

- Strong evidence consistent findings in at least $50 \%$ of high-quality cohort studies.

- Moderate evidence consistent findings in one highquality cohort study and at least $50 \%$ of two or more high-quality cross-sectional studies or at least $50 \%$ of high-quality cross-sectional studies.

- Limited evidence consistent findings in one high-quality cohort study or in at least $50 \%$ of two or more highquality cross-sectional studies.

- Conflicting evidence inconsistent findings among multiple studies.

- No evidence when one low-quality cohort or crosssectional study or no study provided findings for or against an association. 
Table 1 Standardized checklist for the assessment of methodological quality of prospective cohort studies (PC) and cross-sectional studies (CS)

Study objective

1. Positive if the study had a specific and clearly stated objective description

$\mathrm{PC} / \mathrm{CS}$

Study population

2. Positive if the main features of the study population were described (sampling frame and distribution

$\mathrm{PC} / \mathrm{CS}$

of the population according to age and sex)

3. Positive if the participation rate is $>70 \%$ (data presented)

4. Positive if the response at main moment of follow up is $>70 \%$ (data presented)

$\mathrm{PC} / \mathrm{CS}$

Exposure assessment

5. Positive if data are collected and presented about physical activity at work time

$\mathrm{PC}$

6. Method for measuring physical activity: direct measurement and observation $(+)$, interview or questionnaire only $(-)$

$\mathrm{PC} / \mathrm{CS}$

7. Positive if more than one dimension of physical activity is assessed: duration, frequency or amplitude

$\mathrm{PC} / \mathrm{CS}$

8. Positive if data are collected and presented about physical activity at leisure time

$\mathrm{PC} / \mathrm{CS}$

9. Positive if data are collected and presented about a history of neck or back disorders

$\mathrm{PC} / \mathrm{CS}$

10. Positive if the exposure assessment is blinded to disease status

$\mathrm{PC} / \mathrm{CS}$

Outcome assessment

11. Positive if data were collected for at least 1 year

$\mathrm{CS}$

12. Positive if data were collected at least every 3 months or obtained from a continuous registration system

PC

13. Method for assessing neck or back pain: physical examination blinded to exposure status $(+)$, self reported:

$\mathrm{PC}$

specific questions relating to neck and back disability or use of manikin $(+)$, single question $(-)$

Analysis and data presentation

14. Positive if the appropriate statistical model is used (univariate or multivariate model)

$\mathrm{PC} / \mathrm{CS}$

15. Positive if measures of association are presented (OR/RR), including 95\% CIs and numbers in the analysis (totals)

$\mathrm{PC} / \mathrm{CS}$

16. Positive if the analysis is adjusted for confounding or effect modification is studied

$\mathrm{PC} / \mathrm{CS}$

17. Positive if the number of cases in the multivariate analysis is at least 10 times the number of independent variables in the analysis (final model)

\section{Results}

\section{Search strategy}

A total of 17 articles were judged to meet the selection criteria and were included in the methodological quality assessment (Fig. 1). There were 5 prospective cohort studies $[17,33,37,41,47]$ and 12 cross-sectional studies [3-6, 9, 14, 20, 24, 29, 36, 39, 46]. For cohort studies, the follow-up periods were more than 2 years except one study that followed-up 1-4 years [37]. The cohort studies investigated in the general population (1 study), working population (1 study), school children (2 studies), and twin pairs (1 study). The cross-sectional studies examined in the general population (4 studies) and school children (8 studies).

\section{Methodological quality assessment}

One study reported on the initial part of a longitudinal study [9], i.e., the included article only described the crosssectional analysis of the first measurement of this longitudinal study. Consequently, the study was included in this review as a cross-sectional study. The scoring of the two reviewers of the included studies had an agreement rate of $84 \%(67 / 80)$ for cohort studies and 90\% (151/168) for cross-sectional studies. Disagreements were often about items 7 (assessment of dimension of physical activity) and 16 (adjustment for confounding or effect modification). All disagreements were resolved during a consensus meeting.

The results of the methodological quality appraisal are presented in Table 2. The mean score for methodological quality of cohort studies was $60 \%$, with a range of $44-88 \%$. Three studies were scored as high-quality studies, while two studies were scored as low-quality studies. For the cross-sectional studies, the mean score for methodological quality was $65 \%$, with a range of $43-78 \%$. Ten studies were scored as high-quality studies, while two studies were scored as low-quality studies.

Of 13 high-quality studies, the items in the criteria list rated as negative in most studies were physical activity at work time assessment (item 5-62\%), physical activity measurement tool (item 6-85\%), and frequency of data collection during follow-up period (item 12-67\%).

\section{Assessment of physical activity}

One study used an objective instrument (i.e., accelerometer) [47] and 11 studies employed self-reported questionnaires to assess physical activity level. The remaining one 


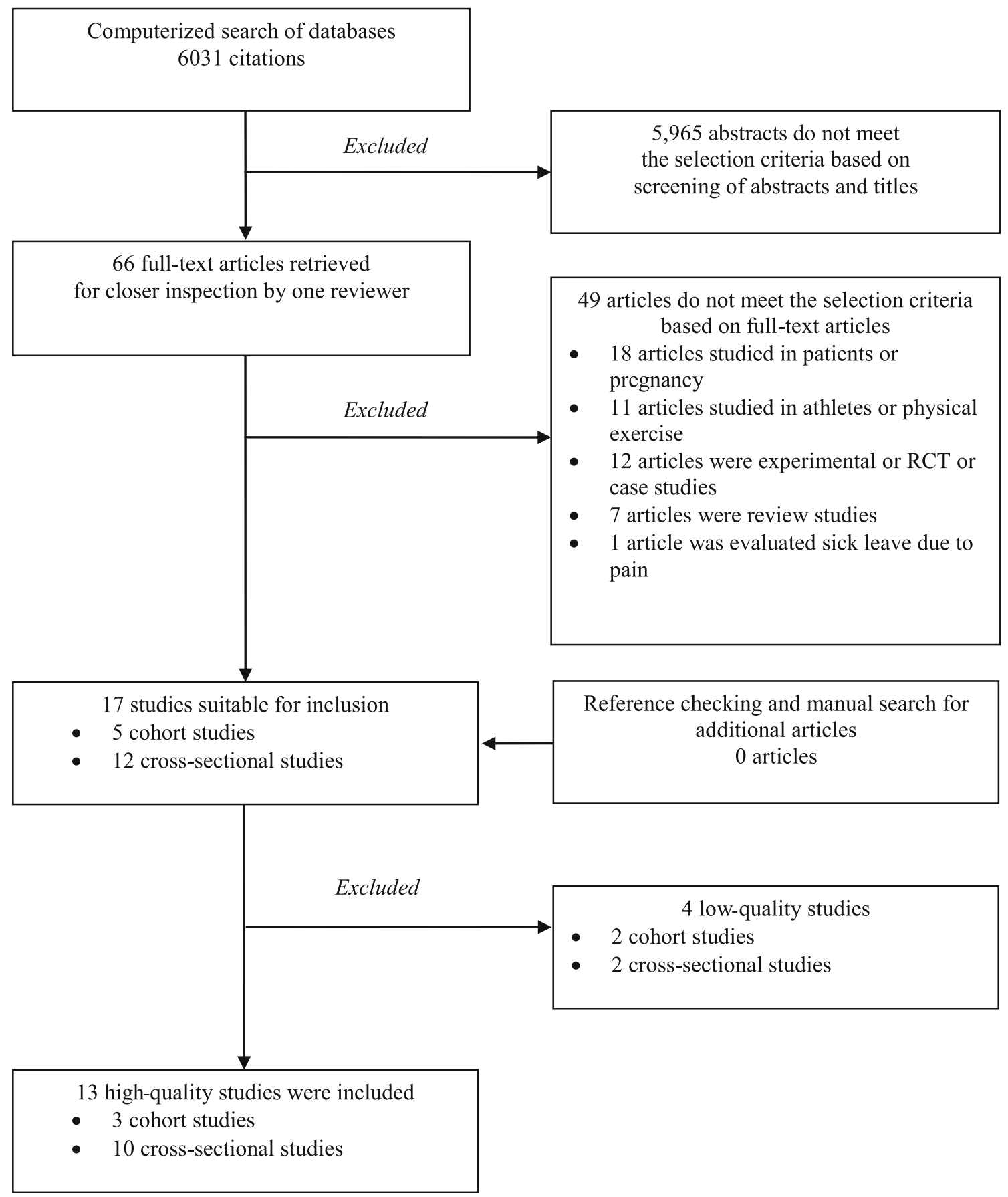

Fig. 1 Flow diagram of the data screening process

study used both self-reported questionnaire and accelerometer [46] (Tables 3, 4).

Nine studies examined physical activity during leisure time. Three studies assessed physical activity at during both work and leisure time. The remaining one study did not clearly specify which setting was examined (Tables 3, 4).
Assessment of neck and low back pain

Two studies examined neck pain only and six studies investigated low back pain only. One study evaluated neck and upper back pain. The remaining four studies measured both neck and low back pain. Eleven studies employed self-reported questionnaires to evaluate neck and/or low 
Table 2 Methodological quality score of the 17 studies (Studies are ranked according to their total scores and, in cases of equal ranking, in alphabetical order of the first author's surname)

\begin{tabular}{|c|c|c|c|c|c|c|c|c|c|c|c|c|c|c|c|c|c|c|}
\hline Quality item/Study & 1 & 2 & 3 & 4 & 5 & 6 & 7 & 8 & 9 & 10 & 11 & 12 & 13 & 14 & 15 & 16 & 17 & Total score $(\%)$ \\
\hline \multicolumn{19}{|l|}{ Cohort study } \\
\hline Wedderkopp et al. [47] & + & + & $?$ & + & + & + & + & + & + & & + & - & + & + & + & + & + & $14 / 16(88)$ \\
\hline van den Heuvel et al. [41] & + & - & + & $?$ & - & - & - & + & - & & + & + & + & + & + & + & + & $10 / 16(62)$ \\
\hline Mikkelsson et al. [33] & + & + & - & - & - & - & + & + & - & & + & - & - & + & + & + & + & $9 / 16(56)$ \\
\hline Picavet and Schuit [37] & + & - & - & - & + & - & - & + & - & & + & - & $?$ & + & + & + & + & $8 / 16(50)$ \\
\hline Hartvigsen and Christensen [17] & + & $?$ & $?$ & + & $?$ & - & + & $?$ & - & & + & - & + & + & + & - & $?$ & $7 / 16(44)$ \\
\hline \multicolumn{19}{|l|}{ Cross-sectional study } \\
\hline Auvinen et al. [4] & + & + & - & & - & - & + & + & + & + & & & + & + & + & + & + & $11 / 14(78)$ \\
\hline Auvinen et al. [5] & + & + & - & & - & - & + & + & + & + & & & + & + & + & + & + & $11 / 14(78)$ \\
\hline Heneweer et al. [20] & + & $?$ & - & & + & - & + & + & + & + & & & + & + & + & + & + & $11 / 14(78)$ \\
\hline Østerås et al. [36] & + & + & + & & - & - & - & + & + & + & & & + & + & + & + & + & $11 / 14(78)$ \\
\hline Björck-van Dijken et al. [6] & + & + & - & & + & $?$ & + & + & + & $?$ & & & $?$ & + & + & + & + & $10 / 14(71)$ \\
\hline Sjolie [39] & + & + & + & & - & - & + & + & - & + & & & + & + & + & + & $?$ & $10 / 14(71)$ \\
\hline Diepenmaat et al. [14] & + & $?$ & + & & $?$ & - & + & $?$ & + & + & & & + & + & + & $?$ & + & 9/14 (64) \\
\hline Brown et al. [9] & + & - & + & & $?$ & - & + & + & - & + & & & - & + & + & + & $?$ & $8 / 14(57)$ \\
\hline Kujala et al. [29] & + & + & $?$ & & - & - & + & + & + & + & & & + & + & - & $?$ & $?$ & $8 / 14(57)$ \\
\hline Wedderkopp et al. [46] & + & + & + & & - & - & + & + & + & + & & & - & + & - & $?$ & $?$ & $8 / 14(57)$ \\
\hline Jacob et al. [24] & + & - & - & & + & - & - & + & + & + & & & + & + & - & - & $?$ & $7 / 14(50)$ \\
\hline Andersen et al. [3] & + & + & - & & + & - & - & $?$ & + & + & & & $?$ & + & - & $?$ & $?$ & $6 / 14(43)$ \\
\hline
\end{tabular}

back pain and the remaining two studies used interviewing. The recall period for neck and/or low back pain varied greatly ranging from 1 month to lifetime.

Evidence of association between physical activity and neck pain

Of seven high-quality studies, one study investigated the association in working population while six studies examined in school children.

In working population, Van den Heuvel et al. [41] conducted a cohort study and found no association between physical activity during leisure time and neck pain among working populations (Table 3). However, the authors [41] concluded that walking or cycling to work or to a train station at least $150 \mathrm{~min} /$ week might have a favorable effect on neck symptoms.

Two cohort studies and four cross-sectional studies investigated in school children. These studies reported no association between physical activity and neck pain among school children (Table 3). However, Auvinen et al. [4] concluded that high-level physical activity had a trend to increased prevalence of neck pain in girls.

In summary, there was limited evidence for no association between physical activity during leisure time and neck pain among working populations. There was strong evidence indicating no association between physical activity and neck pain in school children.
Evidence of association of physical activity and low back pain

Of ten high-quality studies, three studies investigated the association in the general population while seven studies examined in school children.

In general population, one cross-sectional study found that high level of physical activity at leisure time related to decreased prevalence of low back pain [9]. One crosssectional study reported that high level of physical activity at work combined with low physical activity in leisure time associated with high prevalence of low back pain [6]. The remaining one cross-sectional study found that either high or low levels of physical activity related to increased risk for chronic low back [20] (Table 4).

In school children, one cohort study [33] and one crosssectional study [39] found that a high level of physical activity at leisure time associated with decreased prevalence of low back pain. One cohort study reported a low level of physical activity as a risk for low back pain [47]. On the other hand, two cross-sectional studies found that high to very high levels of physical activity associated with high prevalence of low back pain [5, 29]. Two crosssectional studies $[14,46]$ reported no association between physical activity at leisure time and low back pain (Table 4).

In summary, due to inconsistent findings in multiple high-quality cohort and cross-sectional studies, there was 


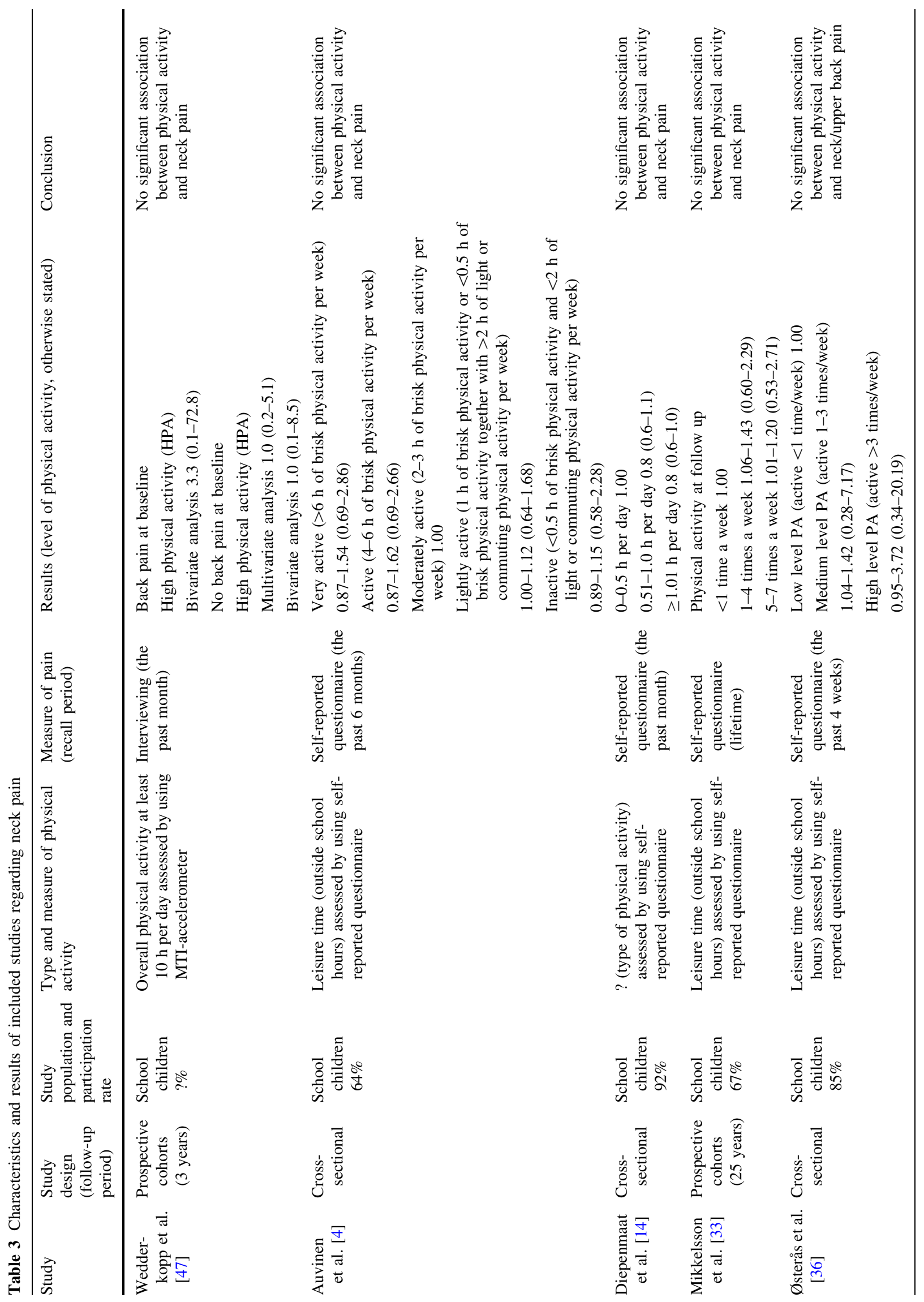




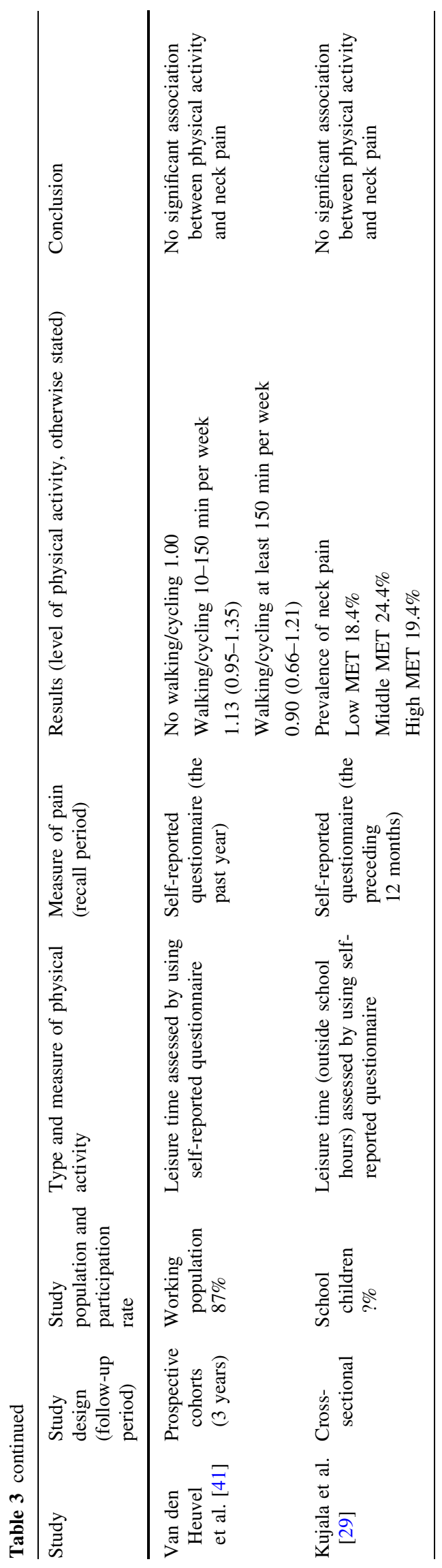

conflicting evidence for the association between physical activity and low back pain in both general population and school children.

\section{Discussion}

This review evaluated the results of 13 high-quality studies on the association between physical activity and neck and low back pain. We found heterogeneity among studies as to aspects such as study design, study population, type of exposures measured, methods of exposure assessment, statistical analysis, and data presentation. Thus, the analysis of the results was limited to qualitative summary. Based on the limited number of studies and the heterogeneity among studies, the results indicated limited evidence for no association between physical activity during leisure time and neck pain in the working population. Strong evidence was found for no association between physical activity and neck pain among school children. Conflicting evidence was found for the association between physical activity and low back pain in both general population and school children.

\section{Methodological considerations}

Of 13 high-quality studies, the items in the criteria list rated as negative in most studies were physical activity at work time assessment, physical activity measurement tool, and frequency of data collection during follow-up period.

Most studies solely measured physical activity level at leisure time, which may not reflect actual daily physical activity. Physical activity at work time should be assessed and included as part of daily physical activity. When physical activity at work is taken into account, workers who have sedentary activity during work, such as office workers, may have considerably different physical activity level compared with workers whose job characteristics are more physically demanding, such as nurses or refuse collectors. Therefore, future research should consider measuring physical activity at both work and leisure time in order to be more representative of an individual's daily physical activity level.

Common physical activity level measurement methods include self-reported questionnaire, interviewing, and objective instrumentation (i.e., an accelerometer). Most studies employed self-reported questionnaire or interviewing. Only 2 out of 13 included studies used objective instruments to assess physical activity level. Many of the subjective methods had problems with reliability and/or validity. Moreover, objective methods were found to report different results than those obtained from subjective methods [44]. Verbunt et al. [40] indicated that self-report 


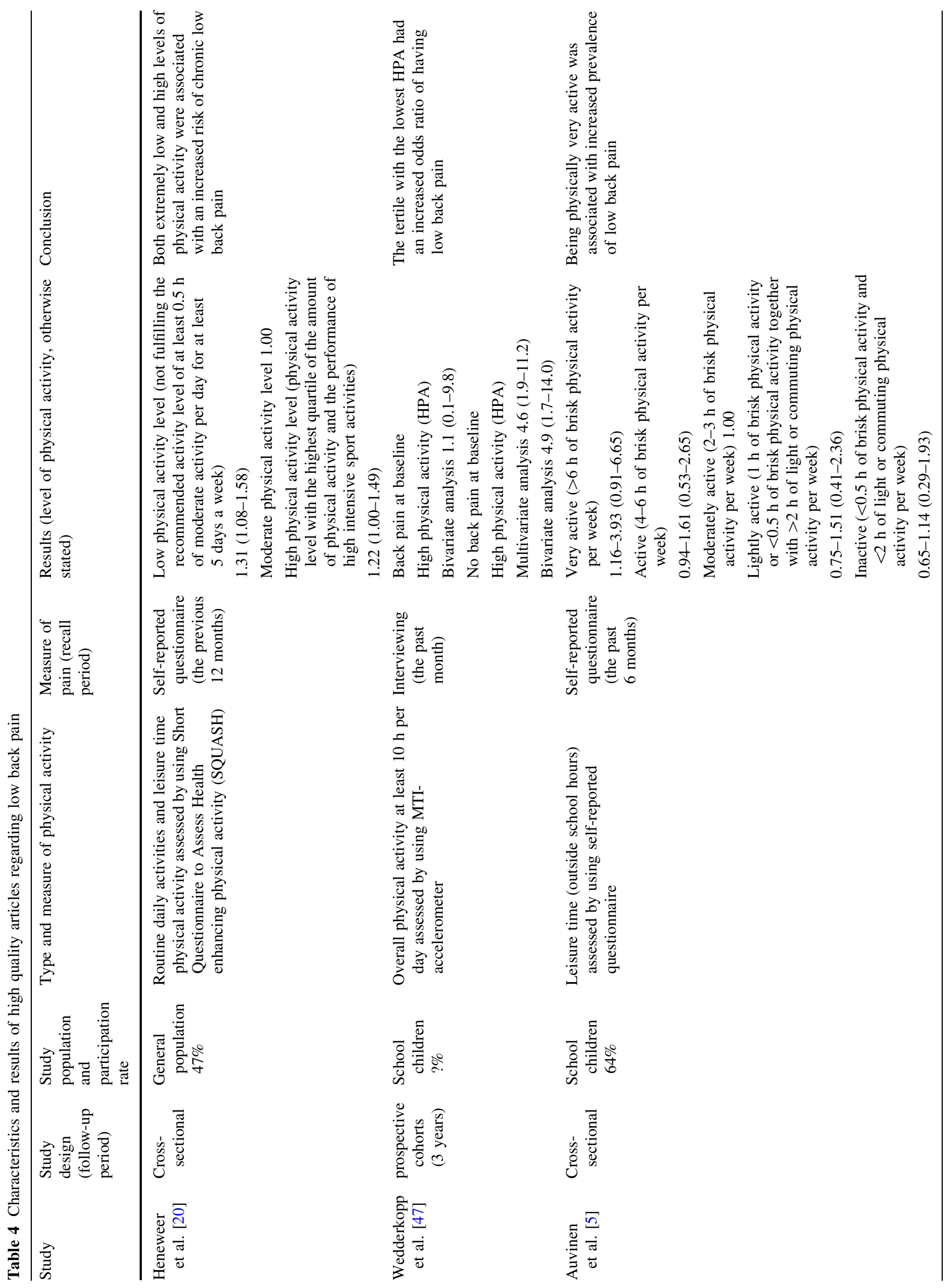




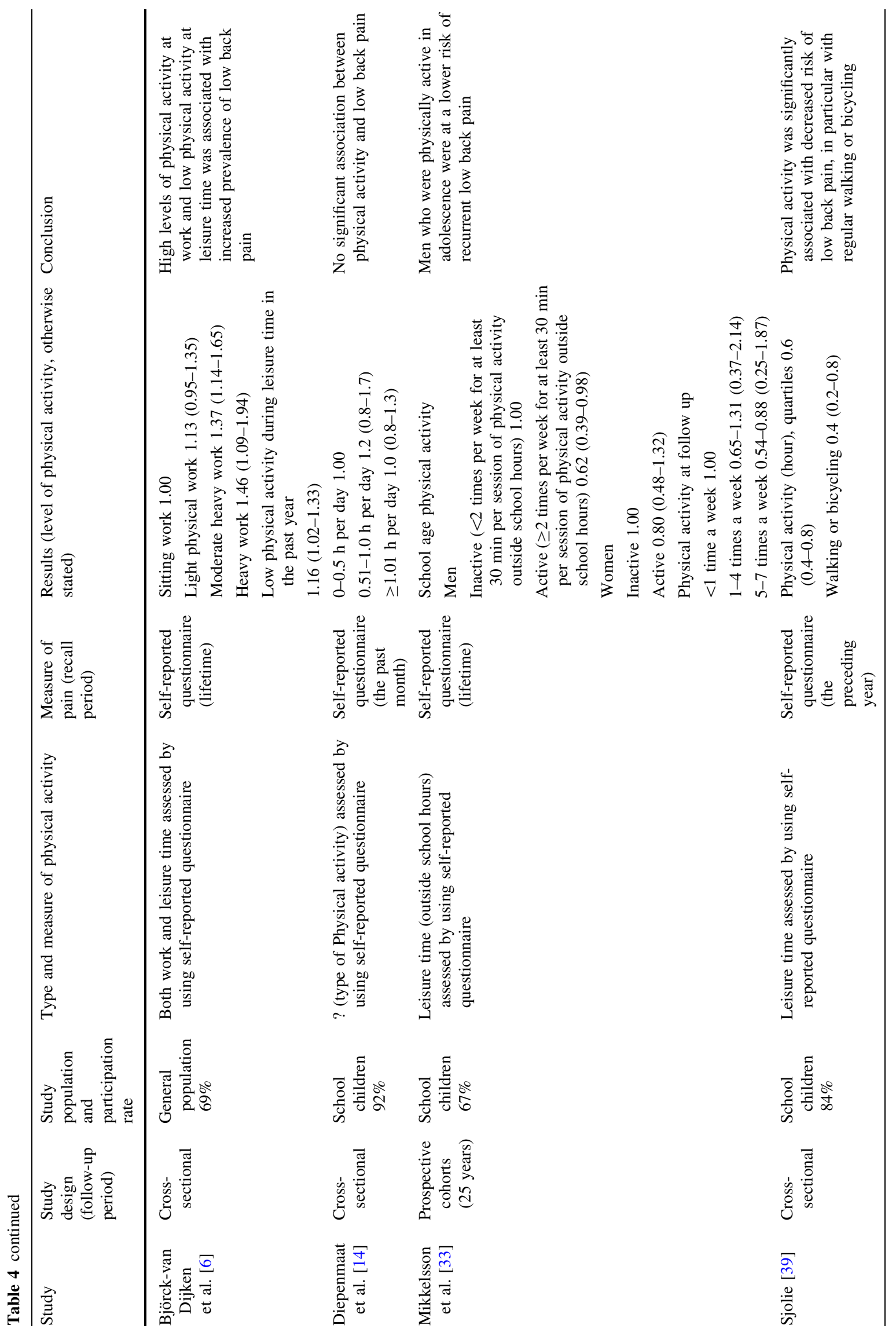




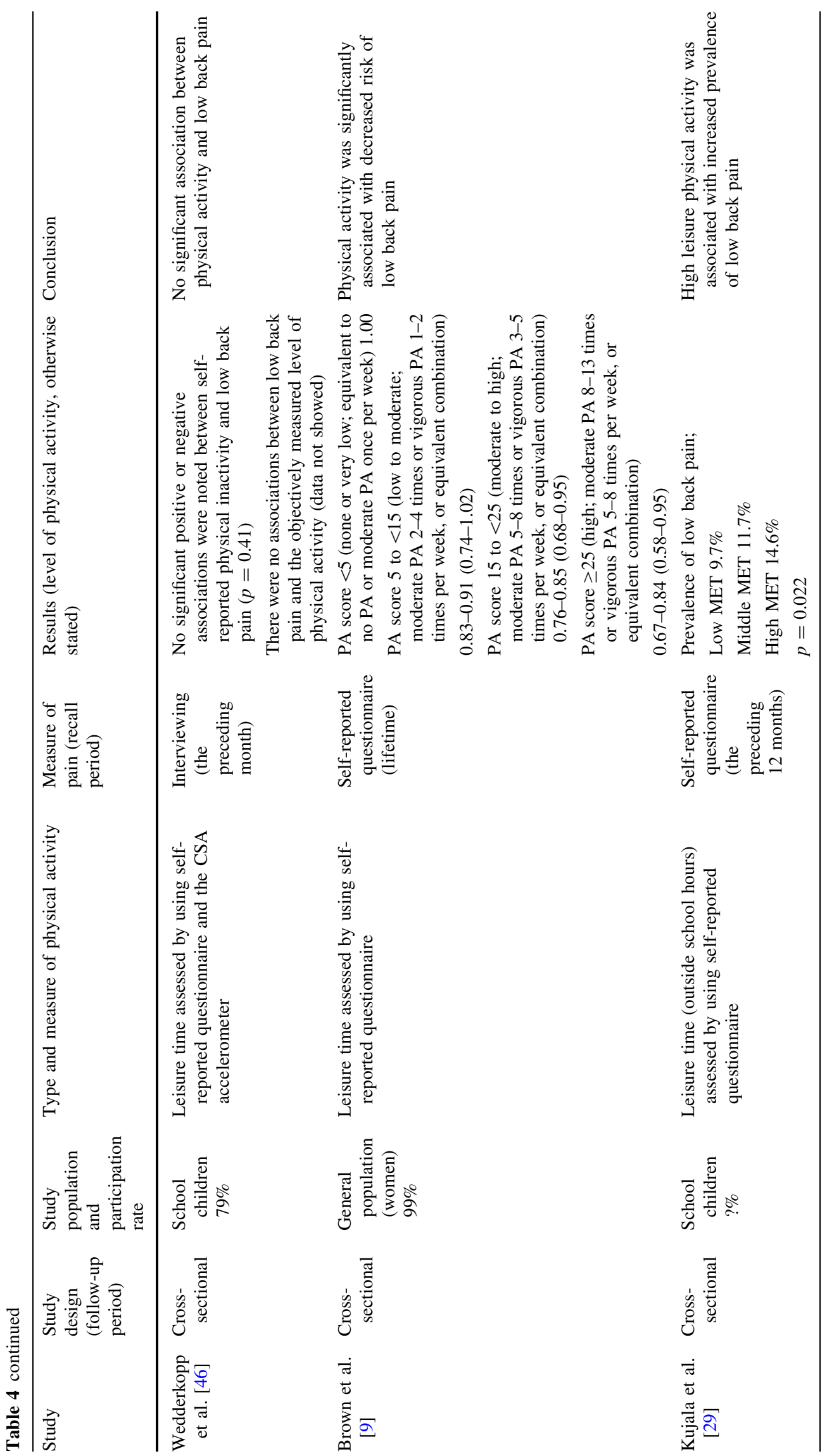


measurements may lead to under- or overestimation of physical activity level, which may result in bias in the association between physical activity and musculoskeletal pain. An objective measure is preferable for assessing physical activity level. Its advantages include having greater validity and providing both quantitative and qualitative assessment of physical activity with minimal burden on participants. During physical activity monitoring, not only mean physical activity levels, but also a classification of physical activities (such as standing, sitting, and locomotion) can be collected. Nowadays, physical activity monitors are becoming more and more convenient. However, high cost and restricted registration time are still barriers. Future research should attempt to use an objective measure to evaluate physical activity level.

The follow-up period of exposure and disease for the studies varied considerably, ranging from 3 to 25 years for physical activity level and from 1 month to lifetime for neck or low back pain. Of three cohort studies, only one study recorded data every year for 3 years [41], whereas the rest of the studies recorded data at the beginning and the end of study only. No data collection regarding exposure and disease during follow-up period may pose a threat of recall bias. This bias may result in an under- or overestimation of the risk of association with an exposure. Kremer et al. [28] reported that patients with pain significantly underestimated their activity level. Schmidt and Brands [38] found that patients were less capable of estimating their physiological level of exertion during a performance test situation than healthy controls. Future studies should pay more attention to the frequency of data collection during their follow-up period, and it is recommended that data are collected at least every 3 months or are obtained from a continuous registration system.

\section{Evidence for association between physical activity} and neck pain

Studies were conducted in substantially varying groups of subjects, including school children, workers, and the general population. One may argue that the effect of physical activity level in different population groups might be different, particularly between adolescents and adults. This seems to be the case for neck pain. When the effect of physical activity level was separately analyzed for workers and school children, there was limited evidence for no association in workers and strong evidence indicating no association in school children.

Performing physical work, adopting awkward working postures and having sedentary lifestyle are common for workers, while such activities are rare in an adolescent population. Epidemiological studies have shown that adopting awkward working postures for prolonged time combined with having sedentary lifestyle have been found to be associated with neck pain [10, 25, 35]. Therefore, increased physical activity level in workers may be beneficial for preventing neck pain. However, the preventive effect of increased physical activity level on neck pain may not be so obvious in adolescents, who usually do not stay in awkward positions [4] and are more physically active than adults [8]. Thus, future research should be more specific regarding the study population and taking the impact of work status on physical activity into account. In addition, due to the low number of high-quality studies, more research is needed to confirm our findings in this respect.

Evidence for association between physical activity and low back pain

The body of evidence regarding the role of physical activity level and low back pain is somewhat more inconsistent than that for neck pain. Even with the separate analysis of the effect of physical activity on low back pain in adolescents and adults, the conflicting evidence still existed. One of the possible explanations for inconsistent findings among studies may relate to heterogeneity in methods of exposure assessment among studies. To assess the physical activity level in patients with musculoskeletal pain, an objective measure is a preferable measurement device to self-report measurement [40]. Wedderkopp et al. [47], who used accelerometers to measure physical activity level, reported that low level of physical activity increased the risk of low back pain in school children. Being physically active may lead to improved physical fitness, which consequently reduces the risk of low back pain and helps the back to function better [33]. However, the rest of the studies employed self-report measurements to examine physical activity level, which are prone to the risk of recall bias. For example, those without low back pain may be more likely to consider themselves to be physically active than those with low back pain or those who are physically active may be more likely to consider their back to be in better condition than those who are less physically active, even if this is not the case [46]. Due to conflicting results, more high-quality studies are needed before a final conclusion can be reached regarding the effect of physical activity on low back pain.

\section{Sensitivity analysis}

Methodological quality of included studies ranged between 43 and $88 \%$, with eight of 17 studies scoring between 43 and $57 \%$. In this review, a priori cut-off point of $>50 \%$ was used, which might have influenced the level of evidence and potentially the results of the review. Thus, we assessed the effect of the cut-off point used in the methodological 
quality assessment on the level of evidence. Shifting the cut-off point from $>50$ to $>60 \%$ or shifting the cut-off point from $>50$ to $>40 \%$ would not have influenced our levels of evidence at all.

The strength of evidence was divided into five levels. However, in an earlier study by Hamberg-van Reenen et al. [16], three levels of evidence were used, i.e., (1) strong evidence: consistent findings in multiple high-quality studies; (2) moderate evidence: consistent findings in one high-quality study and in at least one low-quality study, or consistent findings in multiple low-quality studies; (3) inconclusive evidence: inconsistent findings in multiple studies, or the results based on one or no study provided findings for or against an association. Changing the method to assess the strength of evidence into the one used by Hamberg-van Reenen et al. [16] would not have altered our conclusions.

\section{Limitations of this review}

There are a number of methodological limitations of this systematic review that are noteworthy. First, the search strategy was limited only to full reported publication in English. The possibility of publication and selection bias cannot be ruled out, which may affect the results of the review. Second, we summarized the results from studies with substantial heterogeneity. This may explain the observed variation in the results among studies. Future research is required to indicate whether differences in these aspects affect the association between physical activity on one hand and neck and low back pain on the other. Last, quality assessment tools to appraise observational studies are less well established than those for randomized controlled trials. As no universally accepted quality assessment tool for observational studies exists, the methodological quality assessment used in the present review was based on the assembly of criteria lists in the previous reviews [23, 43]. It is believed that the items included in the criteria list assessed the important components to validate these types of studies.

\section{Conclusions and recommendations}

This review showed limited evidence for no association between physical activity and neck pain in workers, and strong evidence for no association in school children. Conflicting evidence was found for the association between physical activity and low back pain symptoms. More high-quality studies are needed before more definite conclusions can be drawn on the effect of physical activity on neck and low back pain. The design of future studies may be improved by taking into account a number of methodological limitations that are present in the published studies. These include increasing participation rate of samples, using an objective tool to assess physical activity level, measuring physical activity both at work and leisure time, having continuous data collection during the follow-up period, and being more specific regarding study population.

Acknowledgments This work was funded by Chulalongkorn University Centenary Academic Development Project.

Conflict of interest The authors declare that there are no conflicts of interest.

Open Access This article is distributed under the terms of the Creative Commons Attribution Noncommercial License which permits any noncommercial use, distribution, and reproduction in any medium, provided the original author(s) and source are credited.

\section{References}

1. Ainsworth BE, Youmans CP (2002) Tools for physical activity counseling in medical practice. Obes Res 10:69S-75S

2. Allender S, Foster C, Scarborough P, Rayner M (2007) The burden of physical activity-related ill health in the UK. J Epidemiol Community Health 61:344-348

3. Andersen LB, Wedderkopp N, Leboeuf-Yde C (2006) Association between back pain and physical fitness in adolescents. Spine 31:1740-1744

4. Auvinen J, Tammelin T, Taimela S, Zitting P, Karppinen J (2007) Neck and shoulder pains in relation to physical activity and sedentary activities in adolescence. Spine 32:1038-1044

5. Auvinen J, Tammelin T, Taimela S, Zitting P, Karppinen J (2008) Associations of physical activity and inactivity with low back pain in adolescents. Scand J Med Sci Sports 18:188-194

6. Bjorck-van Dijken C, Fjellman-Wiklund A, Hildingsson C (2008) Low back pain, lifestyle factors and physical activity: a population-base study. J Rehabil Med 40:864-869

7. Borghouts JA, Koes BW, Vondeling H, Bouter LM (1999) Costof-illness of neck pain in The Netherlands in 1996. Pain $80: 629-636$

8. Breuer C (2005) Cohort effects in physical inactivity. A neglected category and its health economical implications. J Public Health 13:189-195

9. Brown WJ, Mishra G, Lee C, Bauman A (2000) Leisure time physical activity in Australian women: relationship with well being and symptoms. Res Q Exerc Sport 71:206-216

10. Cagnie B, Danneels L, Van Tiggelen D, De Loose V, Cambier D (2007) Individual and work related risk factors for neck pain among office workers: a cross sectional study. Eur Spine J 16:679-686

11. Chen SM, Liu MF, Cook J, Bass S, Lo SK (2009) Sedentary lifestyle as a risk factor for low back pain: a systematic review. Int Arch Occup Environ Health 82:797-806

12. Côté P, van der Velde G, Cassidy JD, Carroll LJ, Hogg-Johnson S, Holm LW et al (2008) The burden and determinants of neck pain in workers. Results of the bone and joint decade 2000-2010 task force on neck pain and its associated disorders. Eur Spine J 17:S60-S74

13. Croft PR, Lewis M, Papageorgiou AC, Thomas E, Jayson MIV, Macfarlane GJ, Silman AJ (2001) Risk factors for neck pain: a longitudinal study in the general population. Pain 93:317-325 
14. Diepenmaat ACM, van der Wal MF, de Vet HCW, Hirasing RA (2006) Neck/shoulder, lowback, and arm pain in relation to computer use, physical activity, stress, and depression among Dutch adolescents. Pediatrics 117:412-416

15. Fejer R, Kyvik KO, Hartvigsen J (2006) The prevalence of neck pain in the world population: a systematic critical review of the literature. Eur Spine J 15:834-848

16. Hamberg-van Reenen $\mathrm{HH}$, Ariëns GAM, Blatter BM, van Mechelen W, Bongers PM (2007) A systematic review of the relation between physical capacity and future low back and neck/ shoulder pain. Pain 130:93-107

17. Hartvigsen J, Christensen K (2007) Active lifestyle protects against incident low back pain in seniors: a population-based 2-year prospective study of 1387 Danish twins aged 70-100 years. Spine 32:76-81

18. Hayden J, van Tulder MW, Malmivaara A, Koes BW (2010) Exercise therapy for treatment of non-specific low back pain. Cochrane Database Syst Rev

19. Henchoz Y, Kai-Lik So A (2008) Exercise and nonspecific low back pain: a literature review. Joint Bone Spine 75:533-539

20. Heneweer H, Vanhees L, Picavet HSJ (2009) Physical activity and low back pain: a U-shaped relation? Pain 143:21-25

21. Hogg-Johnson S, van der Velde G, Carroll LJ, Holm LW, Cassidy JD, Guzman J et al (2008) The burden and determinants of neck pain in the general population. Results of the bone and joint decade 2000-2010 task force on neck pain and its associated disorders. Eur Spine J 17:39-51

22. Holth HS, Werpen HKB, Zwart JA, Hagen K (2008) Physical inactivity is associated with chronic musculoskeletal complaints 11 years later: results from the Nord-Trøndelag Health Study. BMC Musculoskelet Disord 9:159

23. Hoogendoorn WE, van Poppel MNM, Bongers PM, Koes BW, Bouter LM (2000) Systematic review of psychosocial factors at work and private life as risk factors for back pain. Spine 25:2114-2125

24. Jacob T, Baras M, Zeev A, Epstein L (2004) Physical activities and low back pain: a community-based study. Med Sci Sports Exerc 36:9-15

25. Janwantanakul $P$, Pensri $P$, Jiamjarasrangsi $W$, Sinsongsook $T$ (2009) Associations between prevalence of self-reported musculoskeletal symptoms of the spine and biopsychosocial factors among office workers. J Occup Health 51:114-122

26. Jensen I (2007) Neck pain. Best Pract Res Clin Rheumatol 21:93-108

27. Katz JN (2006) Lumbar disc disorders and low-back pain: socioeconomic factors and consequences. J Bone Joint Surg 88:21-24

28. Kremer EF, Block A, Gaylor MS (1981) Behavioral approaches to treatment of chronic pain: the inaccuracy of patient self-report measures. Arch Phys Med Rehabil 62:188-191

29. Kujala UM, Taimela S, Viljanen T (1999) Leisure physical activity and various pain symptoms among adolescents. $\mathrm{Br} \mathrm{J}$ Sports Med 33:325-328

30. Liddle SD, Baxter GD, Gracey JH (2004) Exercise and chronic low back pain: what works? Pain 107:176-190
31. Maetzel A, Li L (2002) The economic burden of low back pain: a review of studies published between 1996 to 2001. Best Pract Res Clin Rheumatol 16:23-30

32. Maniadakis N, Gray A (2000) The economic burden of back pain in the UK. Pain 84:95-103

33. Mikkelsson LO, Nupponen $\mathrm{H}$, Kaprio J, Kautiainen $\mathrm{H}$, Mikkelsson M, Kujala UM (2006) Adolescent flexibility, endurance strength, and physical activity as predictors of adult tension neck, low back pain, and knee injury: a 25 year follow up study. Br J Sports Med 40:107-113

34. Nguyen HQ, Ackermann RT, Berke EM, Cheadle A, Williams B, Lin E et al (2007) Impact of a managed-medicare physical activity benefit on health care utilization and costs in older adults with diabetes. Diabetes Care 30:43-48

35. Ortiz-Hernández L, Tamez-González S, Martínez-Alcántara S, Méndez-Ramírez I (2003) Computer use increases the risk of musculoskeletal disorders among newspaper office workers. Arch Med Res 34:331-342

36. Østerås N, Ljunggren AE, Gould KS, Wærsted M, Veiersted KB (2006) Muscle pain, physical activity, self-efficacy and relaxation ability in adolescents. Adv Physiother 8:33-40

37. Picavet HSJ, Schuit AJ (2003) Physical inactivity: a risk factor for low back pain in the general population? J Epidemiol Community Health 57:517-518

38. Schmidt AJ, Brands AM (1986) Persistence behavior of chronic low back pain patients in an acute pain situation. J Psychosom Res 30:339-346

39. Sjolie AN (2004) Associations between activities and low back pain in adolescents. Scand J Med Sci Sports 14:352-359

40. Verbunt JA, Huijnen IPJ, Koke A (2009) Assessment of physical activity in daily life in patients with musculoskeletal pain. Eur J Pain 13:231-242

41. van den Heuvel SG, Heinrich J, Jans MP, van der Beek AJ, Bongers PM (2005) The effect of physical activity in leisure time on neck and upper limb symptoms. Prev Med 41:260-267

42. van der Berg-Emons RJ, Schasfoort FC, de Vos LA, Bussmann JB, Stam HJ (2007) Impact of chronic pain on everyday physical activity. Eur J Pain 11:587-593

43. van der Windt DAWM, Thomas E, Pope DP, de Winter AF, Macfarlane GJ, Bouter LM, Silman A (2000) Occupational risk factors for shoulder pain: a systematic review. Occup Environ Med 57:433-442

44. van Weering M, Vollenbroek-Hutten MM, Kotte EM, Hermens HJ (2007) Daily physical activities of patients with chronic pain or fatigue versus asymptomatic controls. A systematic review. Clin Rehabil 21:1007-1023

45. Walker BF (2000) The prevalence of low back pain: a systematic review of the literature from 1966 to 1998. J Spinal Disord 13:205-217

46. Wedderkopp N, Leboeuf-Yde C, Andersen LB, Froberg K, Hansen HS (2003) Back pain in children: no association with objectively measured level of physical activity. Spine 28:2019-2024

47. Wedderkopp N, Kjaer P, Hestbaek L, Korsholm L, Leboeuf-Yde C (2009) High-level physical activity in childhood seems to protect against low back pain in early adolescence. Spine J 9:134-141 